\title{
THE LATE PALEOLITHIC-NEOLITHIC TRANSITION IN KOREA: CURRENT ARCHAEOLOGICAL AND RADIOCARBON PERSPECTIVES
}

\author{
Christopher J Bae \\ Department of Anthropology, University of Hawai'i, 2424 Maile Way, Saunders Hall 346, Honolulu, Hawaii 96822, USA. \\ Corresponding author. Email: cjbae@hawaii.edu. \\ Jong Chan Kim \\ School of Physics, Seoul National University, Seoul 151-742, Korea. Email: jckim@phya.snu.ac.kr.
}

\begin{abstract}
The application of chronometric dating studies in Korean archaeology has lagged behind similar research in China and Japan. The focus of this article is to provide an update on the accelerator mass spectrometry (AMS) radiocarbon dates derived from Korean Paleolithic and Early Neolithic sites. One of the major highlights from recent $\mathrm{AMS}{ }^{14} \mathrm{C}$ studies in Korea is that blade (and microblade) technologies may have diffused directly from Siberia, rather than through northern China as originally thought. In addition, a Neolithic wooden boat has been discovered in Korea that is as old as, if not older than, similar discoveries from eastern China. More detailed archaeological and chronometric studies in Korea in the coming years will certainly clarify many of the points mentioned here. In particular, through more detailed studies, we will be able to further evaluate the causal factors that provided the impetus for the Late Paleolithic-Neolithic transition in Korea.
\end{abstract}

\section{INTRODUCTION}

The application of chronometric dating studies in Korean archaeology has lagged behind similar research in China and Japan. For example, Ono et al. (2002) published several hundred radiocarbon dates from various Japanese Paleolithic sites, while only $29{ }^{14} \mathrm{C}$ dates were reported in the same issue of Radiocarbon for Korean Paleolithic sites (Bae 2002). The focus of this article is to provide an update on the accelerator mass spectrometry (AMS) ${ }^{14} \mathrm{C}$ dates derived from Korean Paleolithic and Early Neolithic sites (see also Bae and Kim 2003). Updated ${ }^{14} \mathrm{C}$ dates for the Korean Middle Neolithic to Bronze Age are provided in our other contribution in this issue (Kim and Bae 2010). Most of the AMS ${ }^{14} \mathrm{C}$ dates reported here were analyzed directly by the AMS laboratory at Seoul National University (SNU-AMS), with other data culled from the published literature. Because of the paucity of interaction between North and South Korean scholars, relatively little is known currently about recent developments in North Korean archaeological research (Norton 2000a). Thus, our discussion focuses on the South Korean record.

\section{Late Paleolithic}

Traditionally, in Korean archaeology the Paleolithic is divided into a 3-stage sequence: Lower, Middle, and Upper, similar to what has been done in China (Ikawa-Smith 1978; Norton 2000a; Gao and Norton 2002; Bae 2002, 2010). However, due to the absence of a distinctive behavioral pattern that would support a "Middle Paleolithic" in Korea (e.g. development of the Levallois technique in most of the western Old World), we suggest the Korean Paleolithic be divided into an Early and Late period, with the division occurring when blade stone tool technologies appear in the Korean Peninsula. When exactly this division occurred in Korea is still a subject of much debate (Bae 2010). Traditionally, the lithics from Sokchangni were often considered to represent the division between the Early and Late Paleolithic, with the boundary occurring around 30,000 BP. However, based on new AMS ${ }^{14} \mathrm{C}$ studies, it is now likely that blade tool technologies appeared in Korea possibly as early as 38,000 BP, as evidence from sites like Yonghodong, Deokso, Hwaderi, and Wolpyeong indicate (Table 1). Of interest here is that Korean Paleolithic researchers often consider blade technology to have reached Korea from Siberia via the Shuidonggou site in northern China (Bae 2010). The problem that arises with this model is that Shuidonggou is now considered to date to $29,000-24,000$ BP

C 2010 by the Arizona Board of Regents on behalf of the University of Arizona Proceedings of the 20th International Radiocarbon Conference, edited by A J T Jull RADIOCARBON, Vol 52, Nr 2-3, 2010, p 493-499 
(Madsen et al. 2001), thus well postdating the earliest appearance of blade technology in the Korean Peninsula (see also Norton and Jin 2009 for discussion). ${ }^{1}$ If the AMS ${ }^{14} \mathrm{C}$ dates from Yonghodong, Deokso, Hwaderi, and Wolpyeong hold up to further scientific scrutiny, it may be possible that blade technology diffused directly from Siberia to Korea skirting China. It should be noted that a small number of Korean scholars (e.g. Seong 2006) argue that blade technology developed indigenously (but see Bae 2010 for critique of this argument).

Another interesting aspect of the Korean Late Paleolithic is that the well-known traditional core and flake tools (Norton et al. 2006) continue to appear in Korea up through the end of the Pleistocene (Bae 2010), a case not unlike China (Chen et al. 2010), particularly southern China (Norton and Jin 2009). It is not clear whether the presence of traditional core and flake technologies in Korea represent population movements from southern China as recently argued by Bae (2010) or represent continuous occupation of the region by the same foraging groups. The more parsimonious explanation is that the pattern represents similar foraging groups moving around the Korean Peninsula during the Late Paleolithic. Irrespective of which model is correct, the boundary between the Early and Late Paleolithic in Korea now appears to be pushed back to between 40,000-35,000 BP.

\section{Early Neolithic}

The nature of the Korean Paleolithic to Neolithic transition is poorly understood, though discussion of the Incipient Neolithic ( 10,000-8000 BP) has been included in a number of recent reviews of the Korean Neolithic (e.g. Choe and Bale 2002; Norton 2007). One factor that should be included in any discussion of the Late Paleolithic-Neolithic transition in Korea is the effect of paleobathymetric variation. For example, Korean geologists (e.g. Park 2001) have suggested that during the last glacial maximum (LGM; marine isotope stage 2: MIS 2), ocean levels may have dropped as much as $140 \mathrm{~m}$. A bathymetric drop of this magnitude would have lead to a drying up of much of the West $\mathrm{Sea} /$ Yellow Sea that currently separates eastern China and the Korean Peninsula. Thus, during the LGM much of that region would have been dry land and would have allowed population movement throughout much of the area (as reviewed by Norton 2007). However, when the climate warmed during the late MIS 2-1 transition sea levels rose and eventually reached the present level. A rise in the bathymetric levels in the region would have led to a necessary decrease in the amount of territory a foraging group could have utilized. This point has been argued by one of us (Norton 2007) to indicate that foraging groups would have become territorially circumscribed and probably provided at least some of the impetus to settle down and begin at least a semi-sedentary lifestyle, eventually leading to full-scale sedentism. It is well-known in Korean archaeology that by the Early Neolithic ( $\sim 8000$ BP), sedentary villages appear in many regions along the coasts and riverways (Nelson 1993; Norton 2000b, 2007; Choe and Bale 2002).

Korean Neolithic peoples' subsistence strategies are often considered to have been broad-spectrum, in that they collected local nuts and plants, hunted wild boar and deer, and utilized resources from the sea and air (Sample 1974; Sohn 1982; An 1991, 1994; Nelson 1993; Norton et al. 1999; Norton 2000b, 2007; Lee 2001; Choe and Bale 2002). There is growing evidence that by the Middle Neolithic, Korean peoples were harvesting plant domesticates on a small scale (Crawford and Lee 2003; An 2004). Indirect evidence for a change in subsistence strategies is present in the change in artifact patterning with the advent of the Incipient Neolithic. For example, fluted projectile points, microblades, and pottery were excavated together at the Kosanni site, the type site for the Incipient

\footnotetext{
${ }^{1}$ As one of the reviewers of this manuscript justifiably pointed out, there was no "Korea" or "China" during the Paleolithic. In the context employed here, we are just referring to the idea that some Korean archaeologists have suggested blade and microblade technology diffused from the "region" of northern China rather than directly from Siberia.
} 


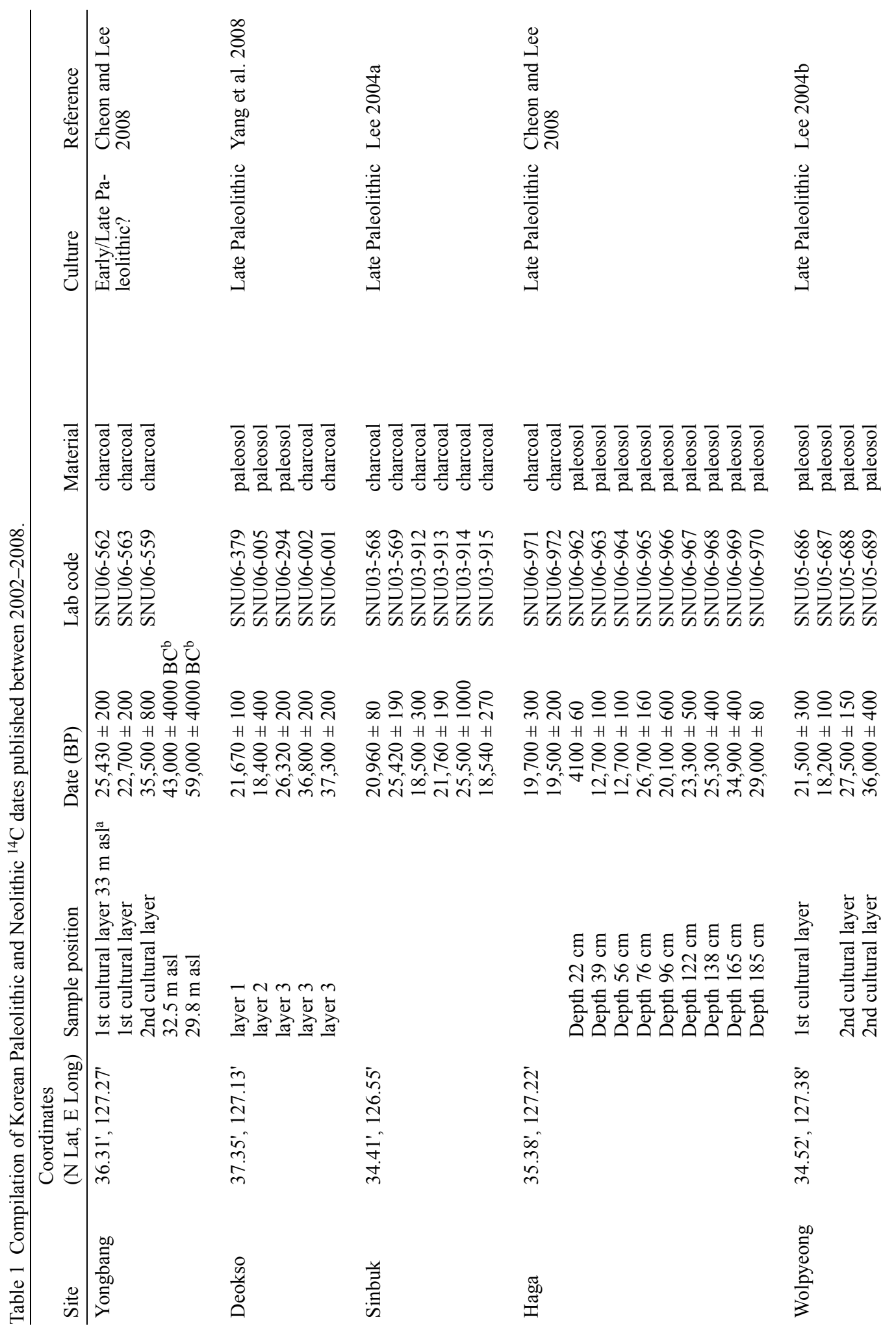




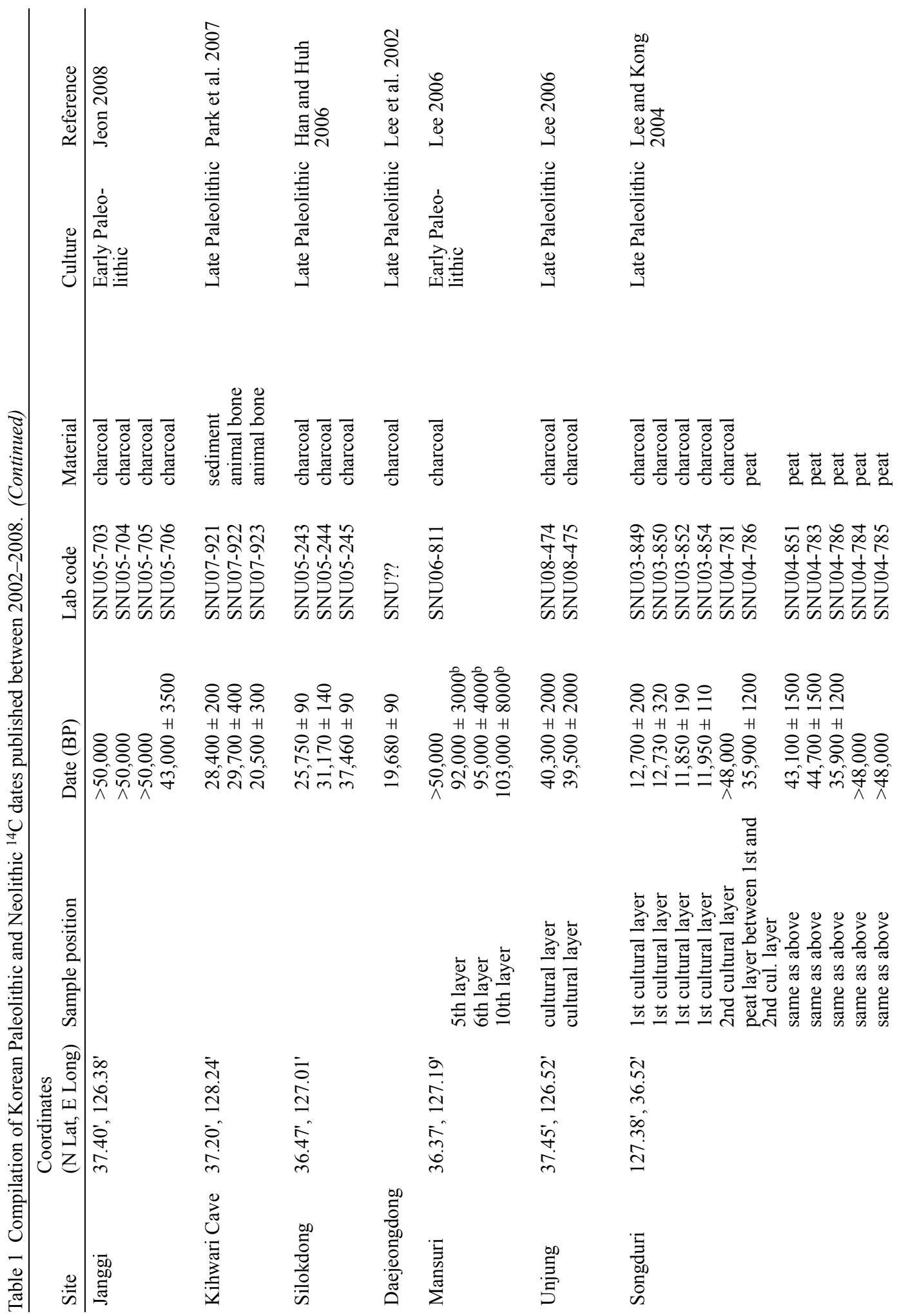




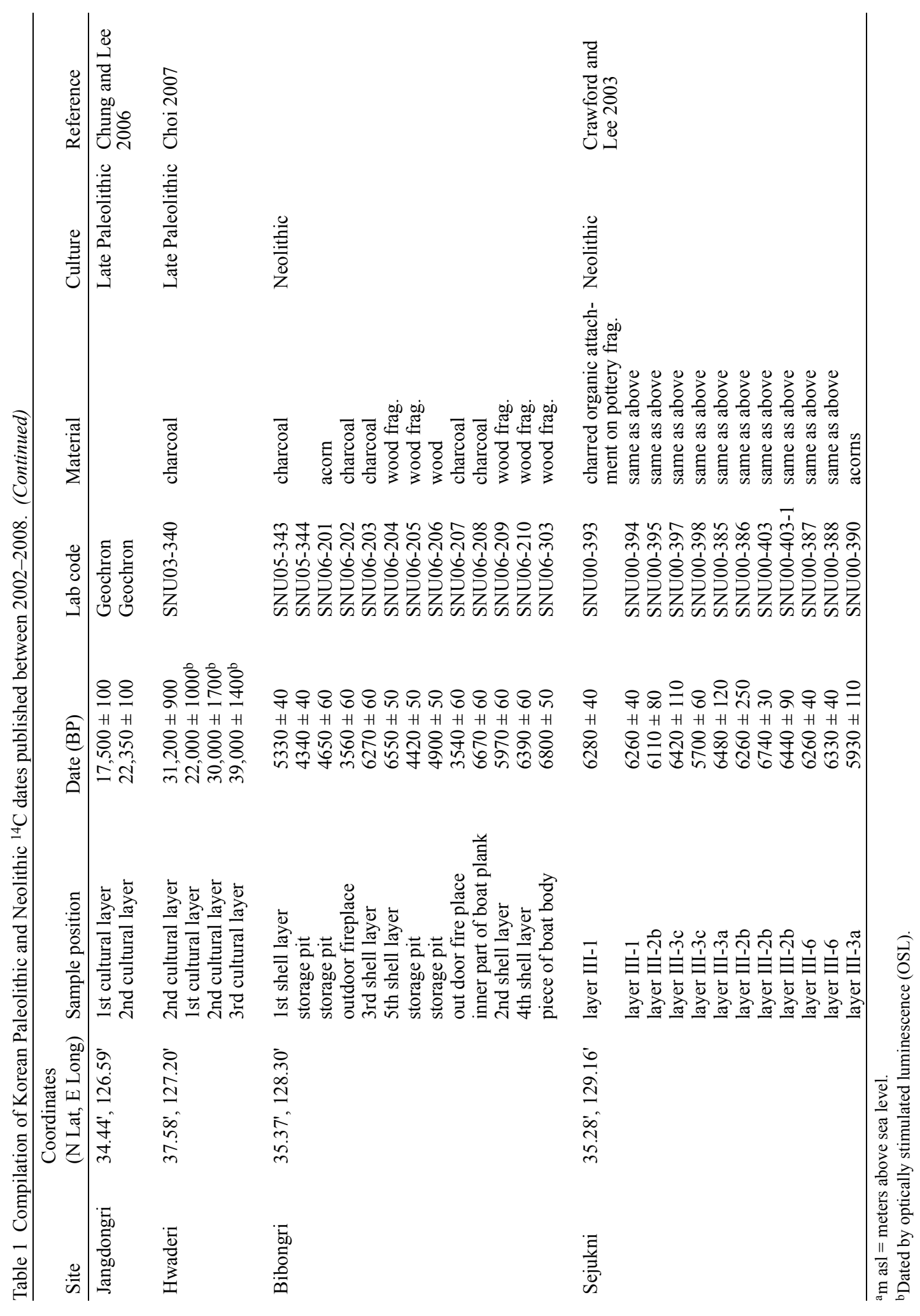


Neolithic in Korea. The artifacts may indicate a heavier emphasis on hunting, while the introduction of pottery suggests a heavier reliance on stored food items.

One major change between the Late Paleolithic and Neolithic in Korea is the appearance of shell middens along the coasts and major river basins. Because shell is very basic in terms of its alkalinity, bone preservation at these sites is excellent. Thus, we know that Neolithic peoples, in addition to collecting a diversity of shellfish, were hunting birds, fishing, and hunting deep-sea mammals. However, it was not until recently that Korean archaeologists found actual evidence of how Neolithic peoples were capable of deep-sea fishing and hunting. Evidence of a wooden boat was discovered during excavations at the Bibongri site, a Neolithic-Bronze Age open-air site located along the southern coast of the Korean Peninsula (Park et al. 2010). Because of the excellent preservation of biological materials at the site, in addition to parts of a wooden boat, many different types of seeds and animal bones were discovered. The AMS ${ }^{14} \mathrm{C}$ dates taken directly from samples of the Bibongri boat indicate it may be as old as $\sim 6800 \mathrm{BP}$ (Table 1). Assuming the AMS ${ }^{14} \mathrm{C}$ dates from Bibongri hold up to further scientific evaluation, the Bibongri boat may be as old as or older than the Neolithic boat from Kuahuqiao (Jiang 2004), which was excavated in eastern China near the Hemudu site. Further studies of the Bibongri site and materials will certainly clarify the position and significance of Bibongri within the East Asian Neolithic. It should be noted that watercraft technology was clearly known in the region going back at least $\sim 40,000-35,000$ yr ago (Ikawa-Smith 2008; Norton and Jin 2009; Norton et al. 2010).

\section{DISCUSSION}

Multidisciplinary approaches are critical to addressing broader ranging archaeological questions. Of the various disciplines usually involved, chronometric studies play an important role in contextualizing archaeological data. One of the major highlights from recent AMS ${ }^{14} \mathrm{C}$ studies in Korea is that blade (and microblade) technologies may have diffused directly from Siberia, rather than through northern China as originally thought. In addition, Korea has evidence of a Neolithic wooden boat that is as old as if not older than similar material from eastern China. More detailed archaeological and chronometric studies in Korea in the coming years will certainly clarify many of the points mentioned here. In particular, through more detailed studies, we will be able to further evaluate the causal factors that provided the impetus for the Late Paleolithic-Neolithic transition in Korea.

\section{ACKNOWLEDGMENTS}

We would like to thank Sarah Nelson for many constructive comments on an earlier draft of this manuscript.

\section{REFERENCES}

An DI. 1991. A study of the Konam-ri shell middens, Korea [PhD dissertation]. London: University of London.

An DI. 1994. Tongsam-dong shell midden and animal remains: focusing on the archaeological data from L. L. Sample's excavation. Journal of the Korean Archaeological Society 31:297-340 In Korean.

An SM. 2004. The beginning of agriculture and sedentary life and their relation to social changes in Korea. In: Cultural Diversity and the Archaeology of the 21st Century. Society of Archaeology Studies, Japan. p 40 61.

Bae KD. 2002. Radiocarbon dates from Paleolithic sites in Korea. Radiocarbon 44(2):473-6.
Bae KD. 2010. Origin and patterns of the Upper Paleolithic industries in the Korean Peninsula and movement of modern humans in East Asia. Quaternary International 211(1-2):103-12.

Bae KD, Kim JC. 2003. Radiocarbon chronology of the Palaeolithic complexes and the transition to the Neolithic in Korea. The Review of Archaeology 24:46-9.

Chen C, An JY, Chen H. 2010. Analysis of the Xiaonanhai lithic assemblage, excavated in 1978. Quaternary International 211(1-2):75-85.

Choe CP, Bale MT. 2002. Current perspectives on settlement, subsistence, and cultivation in prehistoric Korea. Arctic Anthropology 39(1-2):95-121. 
Cheon KH, Lee YJ. 2008. A study of lithic assemblage from the Yong-Bang Paleolithic site. Journal of the Korean Paleolithic Society 17:17-32. In Korean.

Choi BK. 2007. A study on the Hwadae-ri Shimteo Paleolithic site in Pocheon-city, the Korean peninsula. Journal of the Korean Paleolithic Society 15:57-68. In Korean.

Chung CH, Lee HJ. 2006. Palynology of the Pleistocene sediments in Jangdongri Yongdong Paleolthic site, Naju, Korea. Journal of the Korean Paleolithic Society 13:1-8. In Korean.

Crawford GW, Lee GA. 2003. Agricultural origins in the Korean Peninsula. Antiquity 77(295):87-95.

Gao X, Norton CJ. 2002. A critique of the Chinese 'Middle Palaeolithic.' Antiquity 76(292):397-412.

Han CK, Huh EH. 2006. Excavation Report of Asan Silokdong Site. Chungcheong Province Cultural Properties Research Institute. In Korean.

Ikawa-Smith F. 1978. Introduction. In: Ikawa-Smith F, editor. Early Paleolithic in South and East Asia. The Hague: Mouton. p 1-10.

Ikawa-Smith F. 2008. Living on the edge of the continent: the Japanese archipelago 30,000-8,000 cal BC. North Pacific Prehistory 2:45-64.

Jeon BH. 2008. The excavation report at Gimpo Janggidong Paleolithic site. Journal of the Korean Paleolithic Society 17:1-16. In Korean.

Jiang L, editor. 2004. Kuahuqiao. Beijing: Wenwu Press.

Kim JC, Bae CJ. 2010. Radiocarbon dates documenting the Neolithic-Bronze Age transition in Korea. Radiocarbon 52(2-3):483-92.

Lee GK. 2004a. Review of the Upper Paleolithic culture in the Korean Peninsula and Sinbuk Upper Paleolithic site. In: Proceedings of the International Symposium for Commemorating the Sinbuk Upper Paleolithic Site in Janhung County of Korea. Jangheung: Chosun University Museum. p 19-27. In Korean.

Lee GK. 2004b. Wolpyeong, a typical Upper Paleolithic site in Suncheon, Korea. Journal of the Korean Paleolithic Society 9:1-18. In Korean.

Lee GK. 2006. Excavation Report of the Haga Site, Imsil County, Jeollabuk Province, Korea. Volume 1. Chosun University Museum. In Korean.

Lee HJ, Choi JT, Park SH. 2002. Excavation Report of Daejeongdong site. Buried Cultural Properties Research Institute, Korea University. In Korean.

Lee JC. 2006. Cultural patterns of Paleolithic assemblage in Paju-Unjung area. In: Proceedings of the 7th Paleolithic Society Symposium. Yonsei University Museum. In Korean. p 7-18.

Lee JJ. 2001. From shellfish gathering to agriculture in prehistoric Korea: the Chulmun to Mumun transition [PhD dissertation]. Madison: University of Wisconsin.

Lee YJ, Kong SJ. 2004. The Paleolithic culture of the Songduri site. Journal of the Korean Paleolithic Society 10:37-50. In Korean.

Lee YJ, Kong SJ, Park JW, Chon GH. 2006. Mansuri Paleolithic site in Cheongwon: preliminary results. Journal of the Korean Paleolithic Society 14:1-18. In Korean. Madsen DB, Li J, Brantingham PJ, Gao X, Elston RG, Bettinger RL. 2001. Dating Shuidonggou and the Upper Palaeolithic blade industry in North China. Antiquity 75(290):706-16.

Nelson SM. 1993. The Archaeology of Korea. London: Cambridge University Press.

Norton CJ. 2000a. The current state of Korean paleoanthropology. Journal of Human Evolution 38(6):80325.

Norton CJ. 2000b. Subsistence change at Konam-ri: implication for the advent of rice agriculture in Korea. Journal of Anthropological Research 56(3):325-48.

Norton CJ. 2007. Sedentism, territorial circumscription, and the increased use of plant domesticates across Neolithic-Bronze Age Korea. Asian Perspectives 46: 133-65.

Norton CJ, Jin JJH. 2009. The evolution of modern human behavior in East Asia: current perspectives. Evolutionary Anthropology 18(6):247-60.

Norton CJ, Kim BM, Bae KD. 1999. Differential processing of fish during the Korean Neolithic: Konamri. Arctic Anthropology 36(1-2):151-65.

Norton CJ, Bae KD, Harris JWK, Lee HY. 2006. Middle Pleistocene handaxes from the Korean Peninsula. Journal of Human Evolution 51(5):527-36.

Norton CJ, Kondo Y, Ono A, Zhang YQ, Diab M. 2010. The nature of megafaunal extinctions during the MIS 3-2 transition in Japan. Quaternary International 211(1-2):113-22.

Ono A, Sato H, Tsutsumi T, Kudo Y. 2002. Radiocarbon dates and archaeology of the late Pleistocene in the Japanese islands. Radiocarbon 44(2):477-94.

Park GJ, Kim J-C, Youn M, Yun C, Kang J, Song Y-M, Song S-J, Noh H-J, Kim D-K, Im H-J. 2010. Dating the Bibong-ri Neolithic site in Korea: excavating the oldest ancient boat. Nuclear Instruments and Methods in Physics Research B 268(7-8):1003-7.

Park YA. 2001. Korean Quaternary Environment. Seoul: Seoul National University Press. In Korean.

Park YC, Choi MN, Kim SJ, Chung SE. 2007. Preliminary excavation report of the twin cavesite at Kihwa-ri, Mitan-myon, Pyeongchang, Kangwon. Proceedings of the 8th Korea Paleolithic Society Symposium. Kangwon University. p 195-202. In Korean.

Sample LL. 1974. Tongsamdong: a contribution to Korean Neolithic culture history. Arctic Anthropology 11: $1-125$.

Seong CT. 2006. A comparative and evolutionary approach to the Korean Paleolithic assemblages. Journal of the Korean Ancient Historical Society 51:5-42. In Korean.

Sohn PK. 1982. Sangnodaedo Excavation Report. Seoul: Yonsei University Museum In Korean.

Yang JS, Hong MY, Kim JR, Kim NH, Mo HS, Kim JH. 2008. Excavation Report no. 18, The Deokso Site, Nayangju, Gyeonggi Province, Korea. University of Suwon Museum. In Korean. 